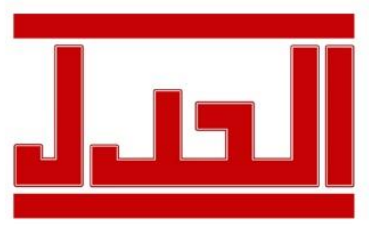

ISSN : $1979-4940$

E-ISSN : $2477-0124$
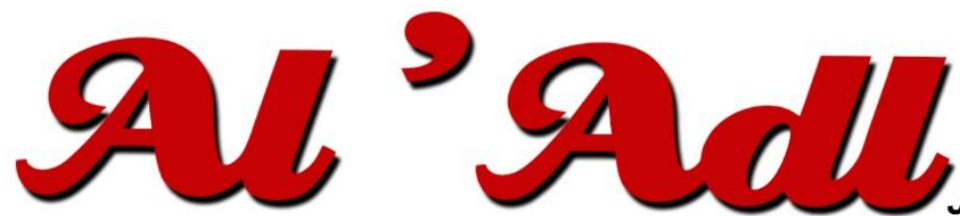

Jurnal Hukum

Editorial Office: Faculty of Law, Islamic University Of Kalimantan,

Jalan Adhyaksa No. 2 Kayutangi Banjarmasin, Kalimantan Selatan, Indonesia (70123)

Email: al_adl@uniska-bjm.ac.id

Web: http://ojs.uniska-bjm.ac.id

\title{
KEBIJAKAN PEMBANGUNAN KESATUAN PENGELOLAAN HUTAN DI INDONESIA: SUATU TEROBOSAN DALAM MENCIPTAKAN PENGELOLAAN HUTAN LESTARI
}

\author{
${ }^{(1)}$ Atika Rahmadanty, ${ }^{(2)}$ I Gusti Ayu Ketut Rachmi Handayani, \\ (3) Fatma Ulfatun Najicha
}

Fakultas Hukum Universitas Sebelas Maret

J1. Ir. Sutami 36A Surakarta, Jawa Tengah 57126

E-mail: ${ }^{(1)} \frac{\text { rahmadantyatika@ } \text { student.uns.ac.id, }^{(2)} \underline{\text { ayu_igk@ } @ \text { fatmanajicha_law@staff.uns.ac.id }}}{{ }^{(3)} \text { stans.ac.id, }}$

\author{
Submitted : 11 November 2020 \\ Revised : : 19 Maret 2021 \\ Accepted : :04 April 2021 \\ Published : 1 Mei 2021
}

(C) Licence by CC BY-NC-SA

\begin{abstract}
The purpose of this study is to find out why forest management through the development policy of the Forest Management Unit (FMU) in Indonesia is needed and what are challenges of developing a Forest Management Unit in Indonesia. This study is normative legal research with primary and secondary legal materials. The results showed that the development policy of the Forest Management Unit (FMU) is needed for the benefit of the community in optimizing the management and utilization of potential funding for climate management of the regional forestry sector either at the provincial, district/city level or management unit level as well. While challenges in developing Forest Management Unit (FMU) in Indonesia including limited human resources $(H R)$, not enough support by local governments, disharmony relationships, social conflicts, and economic interests.
\end{abstract}

Keywords : Forest Management Unit; Protection; Sustainable.

Abstrak
Penelitian ini bertujuan untuk mengetahui mengapa pengelolaan hutan melalui kebijakan pembangunan
Kesatuan Pengelolaan Hutan di Indonesia diperlukan dan bagaimana tantangan pembangunan Kesatuan
Pengelolaan Hutan dalam penyelenggaraan kehutanan di Indonesia. Penelitian ini menggunakan metode
penelitian normatif dengan sumber data berupa bahan hukum primer dan sekunder. Hasil penelitian
menunjukkan bahwa kebijakan pembangunan Kesatuan Pengelolaan Hutan dibutuhkan untuk kepentingan
pembangunan masyarakat dalam pengoptimalan pengelolaan dan pemanfaatan potensi pendanaan
penanganan iklim sektor kehutanan daerah baik tingkat provinsi, kabupaten/ kota atau tingkat unit
pengelolaan serta tantangan dalam penyelenggaraan hutan di Indonesia diantaranya keterbatasan Sumber


Daya Manusia (SDM) profesional, dukungan pemerintah daerah yang belum optimal, adanya disharmonisasi hubungan, adanya konflik sosial dan kepentingan ekonomi.

Kata Kunci: Kesatuan Pengelolaan Hutan; Perlindungan; Lestari.

\section{PENDAHULUAN}

Keberadaan lingkungan hidup sebagai warisan alam tidak dapat dipungkiri memiliki nilai strategis bagi kelangsungan kehidupan makhluk di bumi, termasuk pula manusia yang ada di dalamnya. Setiap orang diwajibkan saling menghormati dan menghargai satu sama lain guna dapat memiliki dan merasakan lingkungan hidup yang sehat. ${ }^{1}$ Hutan merupakan salah satu lingkungan hidup yang berkaitan langsung dengan manusia. Hutan merupakan suatu kesatuan ekosistem berupa hamparan lahan berisi sumber daya alam hayati yang didominasi oleh pepohonan dalam persekutuan alam lingkungannya, yang satu dengan yang lainya tidak dapat dipisahkan. ${ }^{2}$

Pada tahun 2019 Indonesia menduduki peringkat ke-9 dunia sebagai salah satu wilayah yang memiliki sumber daya hutan dengan luas yaitu 94,1 juta hektare atau 50,1\% dari total daratan. ${ }^{3}$ Dari jumlah tersebut, $92,3 \%$ dari total luas berhutan atau 86,9 juta hektare, berada di dalam kawasan hutan. ${ }^{4}$ Indonesia dikenal sebagai pemilik $17 \%$ spesies dunia, walaupun luas wilayahnya hanya $1.3 \%$ dari luas wilayah dunia, ${ }^{5} 11 \%$ spesies tumbuhan berbunga yang sudah diketahui, 12\% mamalia, 15\% amfibi dan reptilia, 17\% jenis burung dan sekitar $37 \%$ jenis-jenis ikan yang ada di dunia. ${ }^{6}$

Pada rentang tahun 2013 hingga 2017 angka deforestasi ${ }^{7}$ hutan alam di Indonesia sebesar 5,7 juta hektare dengan 2,8 juta hektare berada dalam konsesi dan 2,9 juta hektare lainnya berada di luar konsesi. Berbeda halnya dengan angka yang dikeluarkan oleh

\footnotetext{
${ }^{1}$ Eko Nurmadiansyah, (2015), Konsep hijau: Penerapan green Constitution dan Green Legislation dalam rangka eco democracy. Veritas et justitia. Vol 1. Hal 183 -219. DOI: 10.25123/vej.1422, hlm. 200.

${ }^{2}$ Lihat pada Pasal 1 Undang-Undang Nomor 41 Tahun 1999 tentang Kehutanan.

${ }^{3}$ Berdasarkan data Direktorat Jenderal Planologi Kehutanan dan Tata Lingkungan pada tahun 2019.

${ }^{4}$ Hutan Dan Deforestasi Indonesia Tahun 2019, disampaikan oleh Direktur Jenderal PKTL Sigit $\begin{array}{llllll}\text { Hardwinarto } & \text { kepada } & \text { pers } & \text { pada } & 23 & \text { April }\end{array}$ http://ppid.menlhk.go.id/siaran_pers/browse/2435\#: :text=Berdasarkan\%20data\%20Direktorat\%20Jenderal \%20Planologi,\%2C1\%25\%20dari\%20total\%20daratan (diakses pada tanggal 14 Maret 2021).

${ }^{5}$ Berdasarkan data Direktorat Jenderal Planologi Kehutanan dan Tata Lingkungan Kementerian Lingkungan Hidup dan Kehutanan.

${ }^{6}$ Berdasarkan data Kesatuan Lingkungan Hidup dan UNESCO, 1992.

${ }^{7}$ Wikipedia,

https://id.wikipedia.org/wiki/Pengawahutanan\#: :text=Pengawahutanan $\% 2 \mathrm{C} \% 20$ penghilangan $\% 20$ hutan $\% 2$ C\%20penggundulan\%20hutan,pertanian\%2C\%20peternakan\%20atau\%20kawasan\%20perkotaan,

Pengawahutanan, penghilangan hutan, penggundulan hutan, atau deforestasi adalah kegiatan penebangan hutan atau tegakan pohon (stand of trees) sehingga lahannya dapat dialihgunakan untuk penggunaan nir-hutan (non-forest use), yakni pertanian, peternakan atau kawasan perkotaan.
} 
Kementrian Lingkungan Hidup dan Kehutanan menyatakan bahwa deforestasi di Indonesia terus berkurang pada rentang tahun 2013 hingga 2017 yaitu seluas 2,7 juta hektare. Tren deforestasi hutan baik di dalam maupun di luar kawasan hutan Indonesia relatif lebih rendah dan cenderung stabil dengan nilai deforestasi netto tahun 2018 hingga 2019, adalah sebesar 462,4 ribu hektare berasal dari angka deforestasi bruto sebesar 465,5 ribu hektare dengan dikurangi angka reforestasi (hasil pemantauan citra satelit) sebesar 3,1 ribu hektare. Luas deforestasi tertinggi terjadi di kelas hutan sekunder, yaitu 162,8 ribu hektare, di mana 55,7\% atau 90,6 ribu hektare berada di dalam kawasan hutan dan sisanya seluas 72,2 ribu hektare atau 44,3\% berada di luar kawasan hutan.

Sebagai pembanding, hasil pemantauan hutan baik di dalam dan di luar kawasan hutan Indonesia pada tahun 2018 menunjukkan bahwa deforestasi netto tahun 2017 hingga 2018 adalah sebesar 439,4 ribu hektare, yang berasal dari angka deforestasi bruto sebesar 493,3 ribu hektare dengan dikurangi reforestasi (hasil pemantauan citra satelit) sebesar 53,9 ribu hektare, dapat dilihat bahwa secara netto deforestasi Indonesia tahun 2018 hingga 2019 terjadi kenaikan sebesar 5,2\%, namun demikian untuk deforestasi bruto terjadi penurunan sebesar 5,6\%. Oleh sebab itu, jika hutan tidak dikelola dengan bijaksana dan berkelanjutan sesuai kebijakan dan Peraturan Perundang-Undangan yang jelas sudah tentu kemewahan tersebut akan punah. Hutan Indonesia mempunyai tiga fungsi, yaitu: fungsi konservasi, fungsi lindung, dan fungsi produksi.

Perlindungan hutan saat ini sudah memasuki ranah permasalahan dunia (global) terkait dengan fungsi hutan dalam memelihara keseimbangan ekologis yang berpengaruh terhadap iklim global (efek panas global) yang dapat mengancam keselamatan manusia di dunia. Menjaga kawasan hutan dan lingkungannya agar fungsi hutan lindung, fungsi konservasi dan fungsi produksi dapat tercapai secara optimal dan lestari merupakan tujuan dari upaya perlindungan hutan. ${ }^{8}$ Namun pada kenyataannya seringkali fungsi hutan dalam memelihara keseimbangan ekologis (termasuk iklim global) dikalahkan oleh fungsi ekonomi hutan sebagai sumber mata pencaharian hidup bagi sekelompok masyarakat, sebagai sarana mengakumulasi kapital (modal) bagi pengusaha (kapitalis), dan sebagai sumber devisa bagi negara. Salah satu faktor yang turut mempercepat kerusakan hutan adalah peningkatan jumlah penduduk peningkatan jumlah penduduk menuntut

${ }^{8}$ Dewi Gunawati, Harmonisasi Hukum Perlindungan dan Pengelolaan Hutan dalam Upaya Mitigasi Perubahan Iklim Global (Studi Implementasi Program Reducing Emmision from Deforestation and Forest Degradation di Taman Nasional Meru Betiri Jember Jawa Timur), 2015, Surakarta, hlm. 146. 
terpenuhinya kebutuhan pangan, kebutuhan kayu bakar, kebutuhan kayu pertukangan, dan tempat pemukiman. ${ }^{9}$

Adapun penegakan hukum kehutanan yang baik perlu diwujudkan mengingat masalah lingkungan yang semakin meningkat seiring dengan perkembangan industri dan jumlah penduduk terutama di negara-negara berkembang. ${ }^{10}$ Bahwa kualitas lingkungan yang semakin rusak tidak dapat diperbaiki dan dipulihkan $100 \%$ kembali seperti sediakala. ${ }^{11}$ Walaupun Undang-Undang Nomor 41 Tahun 1999 tentang Kehutanan telah mencakup penalisasi terhadap perusakan hutan. ${ }^{12}$ Namun berdasarkan data yang tercatat di Forest Watch Indonesia sejak tahun 2000 hingga tahun 2017, Indonesia telah kehilangan hutan alam lebih dari 23 juta hektare atau sebanding dengan 75 kali luas Provinsi Yogyakarta. Kondisi hutan alam yang terus mengalami kemerosotan merupakan akumulasi dari lemahnya tata kelola hutan yang terjadi dari tahun ke tahun yang berakibat hilangnya hutan alam seluas 1,4 juta hektare/ tahun pada rentang tahun 2000 hingga 2009, menurun pada rentang tahun 2009 hingga 2013 luasan hutan alam yang hilang menjadi 1,1 juta hektare/ tahun dan kembali naik pada rentang tahun 2013 hingga 2017 menjadi 1,4 juta hektare/ tahun. Hasil temuan ini pasti menjadi peringatan keras bagi pemerintah khususnya Kementerian Lingkungan Hidup dan Kehutanan agar lebih bersungguh-sunggih dalam menjaga keberlangsungan hajat hidup rakyat Indonesia dengan mencegah kerusakan hutan alam Indonesia. Bahwa Indonesia sebagai negara yang menjamin pemenuhan hak atas lingkungan hidup yang sehat melalui pengelolaan sumber daya yang melimpah harus melaksanakan upaya pelestarian dengan tata kelola yang baik. ${ }^{13}$

Beberapa instrumen dalam upaya penurunan laju deforestasi seperti izin konsesi pemanfaatan kayu berupa sertifikasi Pengelolaan Hutan Produksi Lestari (PHPL) dan Verifikasi Legalitas Kayu (VLK) juga belum mampu menjawab permasalahan deforestasi yang terjadi di konsesi Izin Usaha Pemanfaatan Hasil Hutan Kayu (selanjutnya disebut

${ }^{9}$ Gunggung Senoaji, (2011), Kondisi Sosial Ekonomi Masyarakat Sekitar Hutan Lindung Bukit Daun Di Bengkulu, Vol. 13, Jurnal Unpad, hlm.

${ }^{10}$ M. Yasir Said dan Ifrani, (2019), Pidana Kehutanan Indonesia, Bandung: Nusa Media, hlm. 1-8

${ }^{11}$ Stewart, Richard and James E Krier dalam M. Yasir Said dan Yati Nurhayati, (2020), "Paradigma Filsafat Etika Lingkungan Dalam Menentukan Arah Politik Hukum Lingkungan", Jurnal Al Adl Volume VII Nomor 1 Januari 2020, hlm. 40

${ }^{12}$ Ifrani, F.A.Abby, A.H.Barkatullah, Yati Nurhayati, M.Yasir Said, (2019), "Forest Management Based on Local Culture of Dayak Kotabaru in the Perspective of Customary Law for a Sustainable Future and Prosperity of the Local Community", Resources, Vol. 8 (Issue 2), hlm. 78. Lihat juga Ifrani dan Yati Nurhayati, (2017), "The Enforcement of Criminal Law in the Utilization and Management of Forest Area Having Impact Toward Global Warming”, Sriwijaya Law Review, Vol.1 Issue.2, July 2017, hlm.157-167.

${ }_{13}$ Egi Agfira Noor, (2020), "Pertanggungjawaban Rumah Sakit Terhadap Limbah Berbahaya Beracun (B3)”, Jurnal Penegakan Hukum Indonesia (JPHI), Vol.1, No.1, Oktober 2020, hlm. 30 
sebagai IUPHHK) (HPH) dan IUPHHK-HT (HTI) yang sudah tersertifikasi sekitar 356 ribu hektare. Dalam IUP perkebunan kelapa sawit, dengan skema ISPO (Indonesia Sustainable Palm Oil) pun ternyata belum terbebas dari deforestasi dengan jumlah 2,3 juta hektare yang sudah bersertifikat ISPO masih terdapat deforestasi sekitar 52 ribu hektare. Konsesi tambang yang terdapat deforestasi sejumlah 700 ribu hektare dan deforestasi di wilayah yang tumpang tindih antara HPH, HTI, kebun dan tambang sekitar 786 ribu hektare termasuk untuk deforestasi di luar konsesi sekitar 2,9 juta hektare.

Lemahnya kelembagaan kehutanan di tingkat lapangan, rapuhnya sistem pengamanan aset sumber daya hutan, administrasi perizinan tanpa kebijakan yang terkendali oleh pemerintah merupakan penyebab permasalahan hutan di Indonesia semakin pelik. Pengelolaan lingkungan dan konservasi sumber daya alam di Indonesia perlu dikaji secara intensif terkait karena pengelolaan lingkungan mustahil tanpa adanya pengaturan hukum. ${ }^{14}$ Pemerintah mengeluarkan kebijakan pembangunan Kesatuan Pengelolaan Hutan (selanjutnya disebut dengan $\mathrm{KPH}$ ) yaitu organisasi yang bekerja di tingkat tapak dan diasakan menjadi litimasi untuk terlaksananya sistem pengelolaan hutan yang lestari dari fungsi ekonomi, fungsi sosial, dan fungsi lingkungan, berkeadilan serta mewujudkan kelestarian dari hutan dapat berjalan secara efisien dan optimal ${ }^{15}$.

\section{RUMUSAN MASALAH}

Berdasarkan latar belakang diatas dan untuk mengetahui seberapa jauh pengelolaan hutan melalui kebijakan pembangunan KPH ini maka perlu diketahui:

1) Mengapa pembangunan KPH di Indonesia diperlukan?

2) Bagaimana tantangan pembangunan KPH dalam penyelenggaraan kehutanan?

\section{METODE PENELITIAN}

Jenis penelitian yang digunakan adalah penelitian hukum normatif, suatu penelitian yang merupakan proses untuk menemukan aturan hukum, prinsip-prinsip hukum yang menjadi permasalahan. Metode pendekatan yang digunakan adalah pendekatan konseptual (conceptual approach) yang berpinjak dari pandangan-pandangan dan doktrin yang

\footnotetext{
${ }^{14}$ Suwari Akhmaddhian, Discourse on Creating a Special Environmental Court in Indonesia to Resolve Environmental Disputes (Wacana Pembuatan Pengadilan Lingkungan Khusus di Indonesia untuk Menyelesaikan Sengketa Lingkungan), 2020, Volume 8, Isuue 2, Jurnal Bestuur, hlm. 20.

${ }^{15}$ Elvida YS dan Iis Alviya. (2009). Kendala dan Strategi Implementasi Pembangunan KPH Rinjani Barat”. Jurnal Penelitian Sosial dan Ekonomi Kehutanan. Volume 6, Nomor 1, hlm. 35.
} 
berkembang, serta pendekatan perundang-undangan (statue approach) dengan menelaah berbagai peraturan perundang-undangan yang memiliki keterkaitan dengan topik penelitian.

Pada hakekatnya, penelitian dalam ilmu hukum berusaha untuk menampilkan perkembangan hukum sesuai dengan kebutuhan kajian ilmu hukum. ${ }^{16}$ Ilmu hukum dalam praktiknya terus mengalami perkembangan seiring dengan perkembangan perilaku masyarakat. Penelitian yang dilakukan dalam konteks ilmu hukum, maka kajian itu adalah tentang permasalahan pada penerapan hukum, proses hukum, peristiwa hukum, dan ketentuan peraturan hukum itu sendiri baik secara substansi maupun prosedural. ${ }^{17}$

Adapun sumber yang digunakan adalah sumber data primer dan sekunder. Sumber data primer terdiri dari Undang-Undang Dasar Negara Republik Indonesia Tahun 1945, Undang-Undang Nomor 5 Tahun 1990 tentang Konservasi Sumber Daya Alam Hayati dan Ekosistemnya, Undang-Undang Nomor 41 Tahun 1999 tentang Kehutanan, dan Peraturan Pemerintah Nomor 6 Tahun 2007 jo Peraturan Pemerintah No 3 Tahun 2008 tentang Tata Hutan, Penyusunan Rencana Pengelolaan Hutan, serta Pemanfaatan Hutan, Peraturan Menteri Kehutanan No P.6/Menhut-II/2009 tentang Pembentukan Wilayah Kesatuan Pengelolaan Hutan. Sedangkan data sekunder meliputi buku teks, jurnal, artikel, dan lain sebagainya. Penelitian ini menggunakan proses berpikir induktif untuk menarik kesimpulan yang bersifat umum dari kasus yang bersifat khusus.

\section{PEMBAHASAN}

\section{A. Pentingnya Kebijakan Pembangunan Kesatuan Pengelolaan Hutan (KPH) di Indonesia}

Disebutkan bahwa bumi, air, dan kekayaan alam yang terkandung di dalamnya dikuasai oleh Negara dan dipergunakan untuk sebesar-besar kemakmuran rakyat. ${ }^{18}$ Secara tidak langsung negara memiliki wewenang (dalam hal ini Pemerintah) untuk mengelola, memanfaatkan, melindungi, dan melestarikan hutan secara berkesinambungan baik generasi sekarang hingga generasi akan datang guna kesejahteraan masyarakat di Indonesia. Hutan dinyatakan sebagai suatu kesatuan ekosistem berupa hamparan berisi

${ }^{16}$ Yati Nurhayati, (2013), Perdebatan Antara Metode Normatif Dengan Metode Empirik Dalam Penelitian Ilmu Hukum Ditinjau Dari Karakter, Fungsi, dan Tujuan Ilmu Hukum, Al Adl: Jurnal Hukum, Vol. 5, No. 10, hlm.15

17 Yati Nurhayati, Ifrani, \& M. Yasir Said, (2021), Metodologi Normatif dan Empiris Dalam Perspektif Ilmu Hukum, Jurnal Penegakan Hukum Indonesia, Vol. 2, No.1, Tahun 2021, hlm.1-20

${ }^{18}$ Lihat pada Pasal 33 Undang-Undang Dasar Negara Republik Indonesia Tahun 1945. 
sumber daya alam haya yang didominasi pepohonan dalam persekutuan alam lingkungannya, yang satu dengan yang lainnya dak dapat dipisahkan. ${ }^{19}$ Hasil hutan diartikan sebagai benda-benda hayati, non-hayati dan turunannya serta jasa yang berasal dari hutan. Kedua pengertian tersebut mengacu pada pengertian bio-fisik hutan dengan penekanan lebih sebagai penghasil kegiatan ekonomi dalam pengelolaan suatu ekosistem. ${ }^{20}$

Pembentukan KPH merupakan entitas pengaturan yang baru dan permanen, dimana secara langsung menangani permasalahan yang ada dan memberikan dasar untuk tata kelola hutan yang lebih baik, perencanaan, co-manajemen sumber daya hutan, pemantauan dan keterlibatan pemangku kepentingan. Selain itu KPH memiliki peran kunci dalam upaya menuju pembangunan berkelanjutan dalam segi ekonomi, mitigasi dan adaptasi perubahan iklim serta konservasi keanekaragaman hayati. ${ }^{21}$ Dengan adanya KPH, integrasi instrumen dan sumber daya yang ada untuk mewujudkan transformasi dan desentralisasi kepemerintahan dan kelembagaan pengelolaan hutan dapat disinergikan. ${ }^{22}$ Pembentukan $\mathrm{KPH}$ diharapkan dapat dijadikan sebagai momentum untuk memperbaiki permasalahan tata kelola kehutanan di Indonesia. ${ }^{23}$

Pembangunan KPH merupakan amanat penting dari Peraturan PerundangUndangan yang mengatur sumber daya hutan. Landasan kebijakan pembangunan KPH didasarkan pada beberapa Undang-Undang, sedangkan landasan pembangunannya diatur dalam sejumlah Peraturan Pemerintan dan landasan teknis penyelengaraannya diatur dalam sejumlah Peraturan Menteri. Kebijakan pembangunan KPH merupakan kegiatan konservasi yang dilakukan untuk mendukung upaya peningkatan kesejahteraan masyarakat dengan menjaga kelestarian, keseimbangan dan pemanfaatan ekosistem sumber daya alam

\footnotetext{
${ }^{19}$ Lihat pada Pasal 1 angka (2) Undang-Undang Nomor 41 Tahun 1999 tentang Kehutanan.

${ }^{20}$ Kementerian Kehutanan Direktorat Jenderal Planologi Kehutanan Direktorat Wilayah Pengelolaan dan Penyiapan Areal Pemanfaatan Kawasan Hutan bekerjasama dengan Deutsche Gesellscha fur Internaonale Zusammenarbeit (GTZ) GmbH, Forest and Climate Change Programme (FORCLIME), Pembangunan Kesatuan Pengelolaan Hutan (KPH) Konsep, Peraturan Perundangan dan Implementasi, Jakarta, Oktober 2011, hlm. 29.

${ }^{21}$ Forest and Climate Change Programme (FORCLIME), Kesatuan Pengelolaan Utan (KPH), "Pertanyaan yang sering diajukan...", http://www.forclime.org/documents/Brochure/Bahasa/FAQ\%20KPH\%20_Bahasa.pdf (diakses pada 02 April 2021).

22 Kartodihardjo H. 2011. Penanganan Konflik Kehutanan: Peran dan Pengalaman Dewan Kehutanan Nasional. Forum DKN untuk Mediasi Konflik. Disampaikan Pada kongres Kehutanan Indonesia (KKI) ke-V Tanggal 21-24 November 2011 di Gedung Manggala Wana Bakti, Jakarta.

${ }^{23}$ Hernowo B. 2011. Pembangunan KPH sebagai priorotas nasional. Direktorat Kehutanan dan Konservasi Sumber daya Air Kementerian PPN/BAPPENAS. Di sampaikan pada Peluncuran Buku KPH Jakarta.
} 
hayati $^{24}$ yang merupakan tanggung jawab dan wewenang dari Pemerintah Pusat, Provinsi dan Kabupaten/ Kota. ${ }^{25}$ Dalam rangka penyelenggaraan pengelolaan hutan tersebut diperlukan pembentukan wilayah pengelolaan hutan yang dilaksanakan pada Tingkat Provinsi, Kabupaten/ Kota dan Unit Pengelolaan. Adapun pengelolaan hutan yang dimaksud meliputi: ${ }^{26}$
a. Tata hutan dan penyusunan rencana pengelolaan hutan;
b. Pemanfaatan hutan dan penggunaan kawasan hutan;
c. Rehabilitasi dan reklamasi hutan; dan
d. Perlindungan hutan dan konservasi hutan.

Dalam rangka menunjang pembangunan berkelanjutan, pengelolaan sumber daya alam dan lingkungan hidup diarahkan agar usaha pendayagunaannya tetap memerhatikan keseimbangan serta kelestarian fungsi dan kemampuannya, sehingga dapat memberikan manfaat yang sebesar-besarnya bagi kehidupan generasi mendatang. Konsep pembangunan berkelanjutan (sustainable development) yang dianut di Indonesia adalah pembangunan yang dapat memenuhi aspirasi dan kebutuhan masyarakat generasi saat ini tanpa mengurangi potensi pemenuhan aspirasi dan kebutuhan generasi mendatang. ${ }^{27}$

Secara konseptual pembangunan KPH merupakan proses pergeseran institusi yang membawa perubahan fundamental pada cara berpikir, sistem nilai dan budaya pengurusan hutan Indonesia. Sebagai sebuah gagasan dalam perbaikan tata kelola hutan, KPH menjadi prioritas nasional yang tertuang dalam Rencana Pembangunan Jangka Menengah (RPJM) Subsektor Kehutanan. Wilayah KPH menjadi salah satu Rencana Strategis pada tahun 2010 hingga tahun 2014 adalah wilayah KPH yang ditetapkan di setiap provinsi dan terbentuk 120 unit dengan luas 16,44 juta hektare yang dilanjutkan oleh Kementerian Lingkungan Hidup dan Kehutanan dengan menyusun Rencana Strategis Target Pembangunan KPH tahun 2015 hingga 2019. Berikut indikator target pembangunan Rencana Pembangunan Jangka Menengah Nasional (RPJMN) tahun 2015 hingga 2019:

${ }^{24}$ Berdasarkan Undang-Undang Nomor 5 Tahun 1990 Tentang Konservasi Sumber Daya Alam Hayati dan Ekosistemnya.

${ }^{25}$ Berdasarkan pada Peraturan Pemerintah Nomor 6 Tahun 2007 jo Peraturan Pemerintah Nomor 3 Tahun 2008 Tentang Tata Hutan, Penyusunan Rencana Pengolahan Hutan, serta Pemanfaatan Hutan.

${ }^{26}$ Lihat pada Pasal 21 Undang-Undang Nomor 41 Tahun 1999 Tentang Kehutanan.

${ }^{27}$ Mukhlis dan Mustafa Lui, Hukum Administrasi Lingkungan Kontemporer Diskursus Pengawasan Pengelolaan Lingkungan Hidup dan Pengembangan Hukum Administrasi di Indonesia, Malang, Setara Press (Kelompok InTRANS Publishing), 2010, hlm. 255-256. 


\begin{tabular}{|c|c|c|c|c|c|c|}
\hline \multirow{2}{*}{ INDIKATOR } & \multicolumn{5}{|c|}{ TARGET } & \multirow{2}{*}{ PENANGGUNG JAWAB } \\
\hline & 2015 & 2016 & 2017 & 2018 & 2019 & \\
\hline $\begin{array}{l}\text { Jumlah KPH yang memiliki peta } \\
\text { Penetapan dan Kelembagaan } \\
\text { Kesatuan Pengelolaan Hutan (KPH) }\end{array}$ & $\begin{array}{l}109 \\
\mathrm{KPH}\end{array}$ & $\begin{array}{l}209 \\
\mathrm{KPH}\end{array}$ & $\begin{array}{l}309 \\
\mathrm{KPH}\end{array}$ & $\begin{array}{l}409 \\
\mathrm{KPH}\end{array}$ & $\begin{array}{l}409 \\
\mathrm{KPH}\end{array}$ & $\begin{array}{l}\text { Direktur Rencana, Penggunaan } \\
\text { dan Pembentukan Wilayah } \\
\text { Pengelolaan Hutan }\end{array}$ \\
\hline $\begin{array}{l}\text { Jumlah KPH yang memiliki } \\
\text { RENCANA PENGELOLAAN }\end{array}$ & $\begin{array}{l}109 \\
\mathrm{KPH}\end{array}$ & $\begin{array}{l}209 \\
\mathrm{KPH}\end{array}$ & $\begin{array}{l}309 \\
\mathrm{KPH}\end{array}$ & $\begin{array}{l}409 \\
\mathrm{KPH}\end{array}$ & $\begin{array}{l}409 \\
\mathrm{KPH}\end{array}$ & $\begin{array}{l}\text { Balai Pemantapan Kawasan } \\
\text { Hutan (BPKH) }\end{array}$ \\
\hline $\begin{array}{l}\text { Jumlah KPHP yang beroperasi } \\
\text { di hutan produksi }\end{array}$ & $\begin{array}{c}80 \\
\text { KPHP }\end{array}$ & $\begin{array}{r}149 \\
\text { KPHP }\end{array}$ & $\underset{\text { KPHP }}{209}$ & $\begin{array}{l}269 \\
\text { KPHP }\end{array}$ & $\begin{array}{l}347 \\
\text { KPHP }\end{array}$ & $\begin{array}{l}\text { Direktur Kesatuan Pengelolaan } \\
\text { Hutan Produksi }\end{array}$ \\
\hline $\begin{array}{l}\text { Jumlah KPHP yang menerapkan } \\
\text { prinsip pengolahan hutan } \\
\text { produksi lestari }\end{array}$ & 2 & $\begin{array}{l}5 \\
\text { KPHP }\end{array}$ & $\begin{array}{c}10 \\
\mathrm{KPHP}\end{array}$ & $\begin{array}{c}15 \\
\text { KPHP }\end{array}$ & $\begin{array}{c}20 \\
\text { KPHP }\end{array}$ & \\
\hline $\begin{array}{l}\text { Jumlah KPHP yang berproduksi } \\
\text { di hutan produksi }\end{array}$ & $\begin{array}{c}80 \\
\text { KPHP }\end{array}$ & $\begin{array}{r}149 \\
\text { KPHP }\end{array}$ & $\underset{\text { KPHP }}{209}$ & $\begin{array}{l}269 \\
\text { KPHP }\end{array}$ & $\begin{array}{l}347 \\
\text { KPHP }\end{array}$ & $\begin{array}{l}\text { Balai Pemantauan Pemanfaatan } \\
\text { Hutan Produksi (BP2HP) }\end{array}$ \\
\hline Jumlah KPHL yang beroperasi & $\begin{array}{c}40 \\
\mathrm{KPHL}\end{array}$ & $\begin{array}{c}80 \\
\mathrm{KPHL}\end{array}$ & $\begin{array}{r}120 \\
\mathrm{KPHL}\end{array}$ & $\begin{array}{l}160 \\
\mathrm{KPHL}\end{array}$ & $\begin{aligned} 182 \\
\mathrm{KPHL}\end{aligned}$ & $\begin{array}{l}\text { Direktur Kesatuan Pengelolaan } \\
\text { Hutan Lindung }\end{array}$ \\
\hline Jumlah KPHL yang beroperasi & $\begin{array}{c}40 \\
\mathrm{KPHL}\end{array}$ & $\begin{array}{c}80 \\
\text { KPHL }\end{array}$ & $\begin{array}{r}120 \\
\mathrm{KPHL}\end{array}$ & $\begin{array}{r}160 \\
\mathrm{KPHL}\end{array}$ & $\begin{array}{r}182 \\
\mathrm{KPHL}\end{array}$ & $\begin{array}{l}\text { Balai Pengelolaan Daerah Aliran } \\
\text { Sungai (BPDAS) }\end{array}$ \\
\hline
\end{tabular}

Sumber: Sekretaris Jenderal Kementerian Lingkungan Hidup dan Kehutanan

Adanya KPH memungkinkan identifikasi keberadaan dan kebutuhan masyarakat terhadap manfaat sumber daya hutan dengan lebih jelas dan cermat, sehingga proses-proses pengakuan hak, ijin maupun kerjasama menjadi lebih memungkinkan untuk dilakukan. ${ }^{28}$ KPH berperan sebagai penyelenggara pengelolaan hutan di lapangan atau di tingkat tapak yang harus menjamin pengelolaan hutan dilakukan secara lestari sesuai dengan fungsinya. $^{29}$

Dengan adanya $\mathrm{KPH}$, integrasi instrumen dan sumber daya yang ada untuk mewujudkan transformasi dan desentralisasi kepemerintahan dan kelembagaan pengelolaan hutan dapat disinergikan. ${ }^{30}$ Pembentukan KPH diharapkan dapat dijadikan sebagai momentum untuk memperbaiki permasalahan tata kelola kehutanan di Indonesia. ${ }^{31}$ Wilayah KPH adalah wilayah pengelolaan hutan yang dibangun di tingkat tapak sesuai

28 OK Hasnanda Syahputra, Bramasto Nugroho, Hariadi Kartodihardjo, Nyoto Santoso, Pembelajaran Dari Kelembagaan Pengelolaan Mangrove Berbasis Masyarakat Di Kesatuan Pengelolaan Hutan Wilayah 3 Provins Aceh, Seminar Nasional Ke-IV Fakultas Pertanian Universitas Samudra "Pertanian Berkelanjutan Berbasis Sumber Daya Lokal di Era Revolusi Industri 4.0”, Volume 2, Nomor 1, 2019, hlm. 16.

${ }^{29}$ Kartodihardjo H., Nugroho B., Putro HR. 2011, Pembangunan Kesatuan Pengelolaan Hutan (KPH): Konsep, Peraturan Perundangan dan Implementasi, Jakarta: Kementerian Kehutanan Republik Indonesia.

30 Kartodihardjo H. 2011. Penanganan Konflik Kehutanan: Peran dan Pengalaman Dewan Kehutanan Nasional. Forum DKN untuk Mediasi Konflik. Disampaikan Pada kongres Kehutanan Indonesia (KKI) ke-V Tanggal 21-24 November 2011 di Gedung Manggala Wana Bakti, Jakarta.

${ }^{31}$ Hernowo B. 2011. Pembangunan KPH sebagai priorotas nasional. Direktorat Kehutanan dan Konservasi Sumber daya Air Kementerian PPN/BAPPENAS. Di sampaikan pada Peluncuran Buku KPH Jakarta. 
dengan fungsi pokok dan peruntukannya agar supaya menjangkau setiap wilayah secara efektif, efisien dan lestari, dimana KPH terdiri dari KPH Konservasi (KPHK), KPH Lindung (KPHL) dan KPH Produksi (KPH Produksi). ${ }^{32}$

Adanya pembangunan KPH ditegaskan bahwa kewenangan penyelenggaraan pengurusan sumber daya hutan diberikan kepada pemerintah yang meliputi pengelolaan hutan mencakup penataan hutan, penyusunan rencana pengelolaan, pemanfaatan, rehabilitasi dan reklamasi, serta perlindungan dan konservasi alam. ${ }^{33}$ Oleh karena itu, pembangunan KPH dibutuhkan agar wilayah pengelolaan hutan baik untuk Tingkat Provinsi, Kabupaten/ Kota, atau Tingkat Unit Pengelolaan dapat terkelola dengan optimal. $^{34}$

Pembentukan KPH merupakan entitas pengaturan yang baru dan permanen, dimana secara langsung menangani permasalahan yang ada dan memberikan dasar untuk tata kelola hutan yang lebih baik, perencanaan, co-manajemen sumber daya hutan, pemantauan dan keterlibatan pemangku kepentingan. Selain itu KPH memiliki peran kunci dalam upaya menuju pembangunan berkelanjutan dalam segi ekonomi, mitigasi dan adaptasi perubahan iklim serta konservasi keanekaragaman hayati. ${ }^{35}$

Kehadiran KPH sebagai organisasi pengelolaan hutan ditingkat tapak, adalah untuk memastikan bahwa klaim atas sumber daya hutan harus memperoleh perlindungan negara (merujuk pada legalitas), begitu pula klaim seseorang atau kelompok harus mampu membangkitkan atau menegakkan kewajiban bagi orang atau kelompok lain untuk menghormati klaim tersebut (merujuk pada legitimasi), dan klaim atas sumber daya akan memerlukan biaya pengelolaan dan penegakan atas hak-hak (merujuk pada kemampuan pendanaan dan penyediaan sumber daya manusia yang memadai). ${ }^{36}$

${ }^{32}$ Lihat pada Pasal 1 Angka 4 Peraturan Menteri Kehutanan Nomor P.6/Menhut-II/2009 tentang Pembentukan Wilayah Kesatuan Pengelolaan Hutan.

${ }^{33}$ Berdasarkan Undang-Undang Nomor 41 Tahun 1999 Tentang Kehutanan.

${ }^{34}$ Hal ini diatur dalam Peraturan Pemerintah Nomor 44 tahun 2004 tentang Perencanaan Kehutanan dengan adanya pembagian kewenangan antara Pemerintah Pusat dan Daerah sesuai dengan Undang-Undang Nomor 23 Tahun 2014 Tentang Pemerintahan Daerah.

${ }^{35}$ Forest and Climate Change Programme (FORCLIME), Kesatuan Pengelolaan Utan (KPH), "Pertanyaan yang sering diajukan", http://www.forclime.org/documents/Brochure/Bahasa/FAQ\%20KPH\%20_Bahasa.pdf (diakses pada 02 April 2021).

${ }^{36}$ Nugroho B, (2014), dalam Setyarso A., Djajono A., Nugroho B., Wulandari C., Suwarno E., Kartodihardjo H., Sadjono MA (ed): "Strategi pengembangan KPH dan perubahan struktur kehutanan Indonesia”, Direktorat Jenderal Planologi Kehutanan, Kementerian Lingkungan Hidup dan Kehutanan, Jakarta. 
Adapun pembagian kewenangan KPH meliputi: KPHK menjadi bagian dari pemerintah pusat sementara KPHL dan KPHP bagian dari pemerintah Provinsi/Kabupaten/Kota. Pembangunan KPH diharapkan dapat menyelenggarakan pengelolaan hutan dengan menjabarkan kebijakan kehutanan Nasional, Provinsi, Kabupaten/Kota. KPH di tingkat tapak yang dekat dengan masyarakat akan memudahkan pemahaman permasalahan riil di lapangan sekaligus memposisikan perannya dalam penetapan bentuk akses yang tepat bagi masyarakat serta saran solusi konflik. Oleh karena itu, apabila dirumuskan peran KPH dalam pembangunan hutan diantaranya:

1. Melaksanakan Kegiatan Pengelolaan Hutan

Prioritas teknis dalam mempertahankan hutan alam yang tersisa maupun membangun hutan tanaman baru untuk mencapai tujuan pengelolaan hutan mencakup:

a. Penyelesaian masalah dan menghindari masalah baru serta meningkatkan kapasitas pengelolaan hutan konservasi dan hutan lindung.

b. Penerima manfaat memperoleh akses yang mudah, alokasi yang adil, biaya yang rendah serta landasan yang kuat.

c. Kelembagaan lokal mendapat penguat berupa infarstruktur sosial, efisiensi ekonomi, akses pemanfaatan sumberdaya hutan, pengembangan nilai tambah hasil hutan.

Sehingga dengan adanya KPH dapat menjembatani optimalisasi pemanfaatan potensi pendanaan penanganan iklim sektor kehutanan untuk kepentingan pembangunan masyarakat.

2. Pemantauan dan penilaian oleh $\mathrm{KPH}$

KPH diharapkan melaksanakan pemantauan dan penilaian atas pelaksanaan kegiatan pengelolaan hutan di wilayahnya, menjamin peningkatan keberhasilan sebelum (pendataan, pemeliharaan, perlindungan, monitoring, dan evaluasi) dan sesudah penanganan rehabilitasi dan reklamasi hutan.

3. Membuka Peluang Investasi

Ketersediaan data (informasi yang detail tingkat lapangan) yang memudahkan dalam investasi pengembangan sektor kehutanan. 
Pengaruh KPH dalam interaksi dengan kelembagaan lokal mendorong revolusi yang dipengaruhi oleh perilaku organisasi sebagai aturan main dalam menerima inovasi, teknologi dan memfasilitasi pembelajaran dan pemberdayaan bersama. Dengan demikian, kelembagaan dibangun untuk menghambat munculnya perilaku oportunistik (opportunistic behaviour) dan saling merugikan; menekan penunggang gratis (free riding) dan pencari keuntungan (rent seeking); memfasilitasi koordinasi, termasuk dalam pertukaran (exchange); dan menekan biaya koordinasi sehubungan kelangkaan informasi yang dimiliki oleh masing-masing pihak yang berhubungan. ${ }^{37}$

Maka pembangunan KPH sebenarnya merupakan wujud desentralisasi pengelolaan hutan namun pemerintah Pusat tetap memiliki andil dalam menetapkan norma, standar, prosedur, kriteria untuk pengelolaan $\mathrm{KPH}$, melaksanakan penetapan pembentukan wilayah dan institusi KPH serta menyusun tata hutan dan rencana pengelolaannya untuk mendukung operasionalisasi KPH. Dengan kawasan hutan yang cukup luas dan produktif sesuai dengan fungsinya, maka beberapa faktor bencana seperti banjir bisa dicegah dalam bentuk ketersedian air bersih hingga udara segar yang dihasilkan oleh tanaman atau pepohonan yang tumbuh di hutan secara alami. ${ }^{38}$

\section{B. Tantangan Pembangunan Kesatuan Pengelolaan Hutan (KPH) dalam Penyelenggaraan Kehutanan}

Proses pembangunan KPH dimulai dengan menyiapkan rancang bangun KPHP dan KPHL oleh Dinas didukung oleh UPT Ditjen Planologi Kehutanan Kementerian Kehutanan dan pertimbangan dari Bupati/ Walikota. Dilanjutkan dengan penyampaian oleh Gubernur kepada Menteri Kehutanan. UPT Dirjen Perlindungan Hutan dan Konservasi Alam (PHKA) dengan dukungan UPT Planologi Kehutanan menyiapkan rancang bangun KPHK yang selanjutnya disampaikan oleh Dirjen PHKA kepada Menteri Kehutanan. Pembangunan wilayah KPH ditentukan berdasarkan beberapa kriteria, meliputi: ${ }^{39}$

a. Kepastian Wilayah Kelola

37 Nugroho B, 2013, Reformasi Kelembagaan dan Tata Kepemerintahan: Faktor Pemungkin Menuju Tata Kelola Kehutanan yang Baik dalam Kartodihardjo H. (ed): "Kembali Ke Jalan Lurus: Kritik Penggunaan Ilmu dan Praktek Kehutanan Indonesia”. ForciDevelopment dan Tanah Air Beta, Yogyakarta.

38 Suriansyah Murhaini, Hukum Kehutanan Penegakan Hukum terhadap Kejahatan di Bidang Kehutanan, Cetakan II, Yogyakarta: Penerbit Laksbang Grafika, 2012, hlm. 9-11.

${ }^{39}$ Direktorat Jenderal Planologi Kehutanan dan Tata Lingkungan Kementerian Lingkungan Hidup dan Kehutanan, 2016, hlm. 9. 
Setelah tahap penunjukan, penataan batas kawasan hutan atau batas wilayah KPH mengikuti batas-batas alam kawasan hutan wajib, dimana setiap areal unit penggunaan dan pemanfaatan harus berada dalam kawasan hutan tetap (letak, luas, dan batas yang jelas dan relatif permanen) yang telah teregistrasi dalam wilayah $\mathrm{KPH}$.

b. Kelayakan Ekologi

Kesesuaian posisi dan letak wilayah KPH terhadap DAS atau Sub DAS; homogenitas geomorfologi dan tipe hutan; dan bentuk areal mengarah ke ideal dari aspek ekologi (areal yang kompak lebih baik dari pada bentuk terfragmentasi dan memanjang).

c. Kelayakan Pengembangan Kelembagaan

Optimum dalam batas rentang kendali luas wilayah; intensitas pengelolaan dari aspek produksi; keutuhan batas izin pemanfaatan hutan dan penggunaan kawasan hutan, serta lembaga pengelolaan hutan yang telah ada menjadi pertimbangan luas wilayah KPH.

d. Kelayakan Pengembangan Pemanfaatan

Areal yang memiliki tingkat fragmentasi yang rendah dan memiliki tingkat aksesibilitas yang memadai menjadi pertimbangan dalam pemanfaatan potensi sumber daya hutan.

Meski KPH sudah berjalan namun dalam kinerja pembangunannya dinilai belum ideal dan masih banyak keterbatasan dalam melakukan operasionalisasi. Keterbatasan tersebut membawa permasalahan internal dan eksternal dalam pembangunan KPH itu sendiri. ${ }^{40}$ Faktor lain yang menyebabkan rusaknya hutan lindung adalah faktor ekonomi masyarakat di sekitar hutan yang digambarkan sebagai masyarakat petani miskin, bahwa penyebab tingginya perambahan hutan adalah motivasi petani untuk memiliki lahan di kawasan hutan lindung. ${ }^{41}$ Adapun menurut Forest Watch Indonesia, beberapa persoalan yang teridentifikasi, antara lain: ${ }^{42}$

\footnotetext{
${ }^{40}$ Elvida Ys, Iis Alviya, 2009, Kendala Dan Strategi Implementasi Pembangunan KPH Rinjani Barat, E-Journal Penelitian Sosial dan Ekonomi Kehutanan, hlm. 8.

${ }^{41}$ Trisna Subarna, Faktor-Faktor yang Mempengaruhi Masyarakat Menggarap Lahan di Hutan Lindung: Studi Kasus di Kabupaten Garut Jawa Barat, Jurnal Penelian Sosial dan Ekonomi Kehutanan, Voume 8, Nomor 4, 2011, hlm. 267.

${ }^{42}$ Forest Watch Indonesia. (2014). Panduan Penilaian Kinerja Pembangunan KPH (Kesatuan Pengelolaan Hutan) di Indonesia.
} 
1. Keterbatasan Sumber Daya Manusia (SDM) profesional di tingkat lapangan secara kualitas dan kuantitas.

Hal ini berkaitan dengan bentuk kelembagaan berupa Unit Pelaksana Teknis Daerah (UPTD) yang lebih dikembangkan oleh daerah daripada bentuk Satuan Kerja Perangkat Daerah (SKPD). ${ }^{43}$ Masalah pengembangan SDM dengan persyaratan administrasi dan kompetensi (pengadaan pegawai, bekal pendidikan teknis dan kecocokan kompetensi profesi) yang sulit.

2. Belum optimalnya dukungan Pemerintah Provinsi/Kabupaten/Kota.

Pemerintah daerah belum memahami fungsi dan manfaat KPH bagi pembangunan daerah, terhambatnya pembangunan KPH di daerah karena kurangnya dukungan pendanaan dan ketidakyakinan pemerintah daerah. Bidang kehutanan (daerah pembangunan KPH) belum menjadi bidang prioritas dalam otonomi daerah. Anggapan terhadap kepala dan staf KPH (pegawai daerah dari pusat) akan membebani keuangan daerah.

3. Berkenaan dengan Disharmonisasi Hubungan

Perlu adanya amandemen dan/ atau addendum peraturan sebagai dasar hukum beroperasinya KPH karena tingkat ketergantungan terhadap arahan dari pusat masih tinggi disebabkan kurangnya kepastian kewenangan, tugas pokok, fungsi, tata hubungan kerja, koordinasi, sinkronisasi, jejaring untuk tukar pembelajaran antara KPH dengan Dinas Kehutanan.

4. Konflik Sosial

Sejumlah alokasi areal pembangunan KPH masih mempunyai konflik lahan yang tinggi. Apabila tidak segera diselesaikan maka semakin lambat masalah-masalah tersebut akan semakin sulit untuk mengatasinya. Permasalahan-permasalahan ini juga dapat menjadi ancaman perpecahan bagi pihak yang terlibat karena perbedaan kepentingan.

5. Kepentingan Ekonomi

Setiap daerah memiliki kekuatan ekonomi masing-masing, kekuatan ekonomi tersebut dapat digunakan untuk menggerakkan KPH. Sehingga pembangunan KPH harus disesuaikan dengaan potensi daerahnya agar dapat memberikan dampak ekonomi bagi daerah tersebut.

Kerusakan terhadap lingkungan hidup dan sumber daya alam seringkali terkait dengan lemahnya akses masyarakat terhadap informasi, baik tentang perubahan kondisi lingkungan hidup maupun pada tingkat pengambilan keputusan yang berpengaruh pada masyarakat, baik yang bersifat umum maupun teknis seperti pemberian izin usaha/ kegiatan. ${ }^{44}$ Selain daripada itu terpadat pula faktor lain yang mempengaruhi pengelolaan hutan lindung di Indonesia, diantaranya: ${ }^{45}$

43 Berdasarkan Peraturan Menteri Dalam Negeri Nomor 61 Tahun 2010 Tentang Pedoman Organisasi dan Tata Kerja Kesatuan Pengelolaan Hutan Lindung dan Kesatuan Pengelolaan Hutan Produksi di Daerah.

${ }^{44}$ Henry Subagio, Jaminan Akses Informasi dalam Perlindungan dan Pengelolaan Lingkungan Hidup (Rekomendasi Penguatan Hak Akses Informasi Lingkungan), Jurnal Hukum Lingkungan Indonesia, Volume 01, Issue 01, Januari 2014, hlm. 75.

${ }^{45}$ Aditia Syaprillah, Sapriani, Pengelolaan Hutan Lindung Kota Tarakan: Perspektif Pembangunan Berkelanjutan, Padjajaran Jurnal Ilmu Hukum (PJIH), Volume 1, Nomor 3, 2014, hlm. 616. 
1. Pemenuhan hidup sehari-hari cenderung menjadi alasan perambahan lahan hutan lindung.

2. Ketidakjelasan legalitas status lahan (sertifikat dari masyarakat) terhadap bilah lahan hutan lindung, pertambangan pasir dan perminyakan.

3. Rendahnya pendidikan dan taraf hidup (ekonomi) masyarakat di sekitar kawasan hutan lindung dan belum adanya kesepahaman terkait dalam hal perencanaan pengelolaan hutan lindung dengan para pihak khususnya masyarakat di sekitar hutan lindung.

Berdasarkan pertimbangan prospek keterjaminan kelancaran proses operasional diperlukan pengaturan posisi-posisi strategis dan penambahan posisi-posisi pendorong atau penyeimbang pada Kemendagri dan Pemda yang ada di dalam tata kelola KPH. ${ }^{46}$ Keterbatasan sumber daya Pemerintah/ Pemerintah Daerah dan masih cukup lemahnya dukungan berbagai pihak akibat keterbatasan pemahaman dan pengetahuan mengenai mengenai KPH menjadi sumber masalah utama pada perkembangan pembangunan KPH. ${ }^{47}$

\section{PENUTUP}

\section{A. Kesimpulan}

Kebijakan pembangunan Kesatuan Pengelolaan Hutan (KPH) memiliki peran sebagai bentuk perlindungan terhadap kelestarian kawasan hutan. KPH merupakan wujud disentralisasi pengelolaan hutan yang berada di tingkat tapak. Melalui KPH sistem pengelolaan hutan dapat terkelola dengan optimal sehingga mewujudkan hutan yang lestari dan berkeadilan. Pembangunan KPH dinilai belum ideal dan masih banyak keterbatasan dalam melakukan operasionalisasi diantaranya keterbatasan Sumber Daya Manusia (SDM) profesional, dukungan pemerintah daerah yang belum optimal, adanya disharmonisasi hubungan, adanya konflik sosial dan kepentingan ekonomi.

\section{B. Saran}

Upaya perlindungan kawasan hutan melalui pembangunan KPH patut untuk diapresiasi. Supaya KPH dapat berjalan dengan ideal sesuai dengan tujuannya,

${ }^{46}$ Eno Suwarno, Hariadi Kartodihardjo, Lala M. Kolopaking, Sudarsono Soedomo, Penggunaan Konsep Rules-In-Use Ostrom Dalam Analisis Peraturan Pembentukan Organisasi Kesatuan Pengelolaan Hutan (The Use of Ostrom's Concept on Rules-in-Use in the Analysis of Regulation of Forest Management Unit Formation), Jurnal Analisis Kebijakan Kehutanan Volume 12, Nomor 1, April 2015, hlm. 18.

47 Direktorat Wilayah Pengelolaan dan Penyiapan Areal Pemanfaatan Kawasan Hutan, 2011, Pembangunan Kestauan Pengelolaan Hutan (KPH) Konsep, Peraturan Perundangan dan Implementasi, Debut Wahana Sinergi, Jakarta, hlm. 4. 
maka permasalahan-permasalahan yang menghambat operasionalisasi pembangunan KPH harus segera diatasi melalui koordinasi, kolaborasi, dan sinkronisasi baik di lingkup daerah maupun pusat. 


\section{Buku}

\section{DAFTAR PUSTAKA}

Direktorat Wilayah Pengelolaan dan Penyiapan Areal Pemanfaatan Kawasan Hutan, (2011), Pembangunan Kestauan Pengelolaan Hutan (KPH) Konsep, Peraturan Perundangan dan Implementasi, Debut Wahana Sinergi, Jakarta.

Kartodihardjo H, Nugroho B, Putro H.R. (2011). Pembangunan Kesatuan pengelolaan Hutan (KPH); Konsep, Peraturan Perundang-Undangan dan Implementasi. Jakarta: Kementerian Kehutanan RI.

Kementerian Kehutanan Direktorat Jenderal Planologi Kehutanan Direktorat Wilayah Pengelolaan dan Penyiapan Areal Pemanfaatan Kawasan Hutan bekerjasama dengan Deutsche Gesellscha fur Internaonale Zusammenarbeit (GTZ) GmbH FORCLIME Forest and Climate Change Programme, (2011), Pembangunan Kesatuan Pengelolaan Hutan (KPH) Konsep, Peraturan Perundangan dan Implementasi, Jakarta.

M. Yasir Said dan Ifrani. (2019). Pidana Kehutanan Indonesia. Bandung: Nusa Media.

Nugroho B, (2013), Reformasi Kelembagaan dan Tata Kepemerintahan: Faktor Pemungkin Menuju Tata Kelola Kehutanan yang Baik dalam Kartodihardjo H. (ed): "Kembali Ke Jalan Lurus: Kritik Penggunaan Ilmu dan Praktek Kehutanan Indonesia". ForciDevelopment dan Tanah Air Beta, Yogyakarta.

Nugroho B, (2014), dalam Setyarso A., Djajono A., Nugroho B., Wulandari C., Suwarno E., Kartodihardjo H., Sadjono MA (ed): "Strategi pengembangan KPH dan perubahan struktur kehutanan Indonesia”, Direktorat Jenderal Planologi Kehutanan, Kementerian Lingkungan Hidup dan Kehutanan, Jakarta.

Peter Mahmud Marzuki, (2010). Penelitian Hukum. Jakarta: Kencana.

Suriansyah Murhaini, (2012), Hukum Kehutanan Penegakan Hukum Terhadap Kejahatan di Bidang Kehutanan, Cetakan II, Penerbit Laksbang Grafika, Yogyakarta.

\section{Peraturan Perundang-Undangan}

Undang-Undang Dasar Negara Republik Indonesia Tahun 1945.

Undang-Undang Nomor 5 Tahun 1990 tentang Konservasi Sumber Daya Alam Hayati dan Ekosistemnya.

Undang-Undang Nomor 41 Tahun 1999 tentang Kehutanan.

Undang-Undang Nomor 32 Tahun 2009 Tentang Perlindungan dan Pengelolaan Lingkungan Hidup. 
Peraturan Pemerintah Nomor 6 Tahun 2007 jo Peraturan Pemerintah No 3 Tahun 2008 tentang Tata Hutan, Penyusunan Rencana Pengelolaan Hutan, serta Pemanfaatan Hutan.

Peraturan Menteri Kehutanan No P.6/Menhut-II/2009 tentang Pembentukan Wilayah Kesatuan Pengelolaan Hutan (KPH).

\section{Jurnal}

Aditia Syaprillah, Sapriani, (2014), Pengelolaan Hutan Lindung Kota Tarakan: Perspektif Pembangunan Berkelanjutan, Padjajaran Jurnal Ilmu Hukum (PJIH), Volume 1, Nomor 3.

Dewi Gunawati. (2015). "Urgensitas Harmonisasi Hukum Perlindungan dan Pengelolaan Hutan dalam Mitigasi Perubahan Iklim Global Melalui Program REDD”. Yustisia. Volume 4, Nomor 1.

Egi Agfira Noor, (2020), "Pertanggungjawaban Rumah Sakit Terhadap Limbah Berbahaya Beracun (B3)", Jurnal Penegakan Hukum Indonesia (JPHI), Vol.1, No.1, Oktober 2020.

Eko Nurmadiansyah. (2015), Konsep Hijau Penerapan Green Constutition dan Green Legislation dalam Rangka Eco Democracy, Jurnal Veritas et Justitia. Volume 1, Nomor 1.

Elvida YS dan Iis Alviya. (2009). "Kendala dan Strategi Implementasi Pembangunan KPH Rinjani Barat". Jurnal Penelitian Sosial dan Ekonomi Kehutanan. Volume 6, Nomor 1.

Eno Suwarno, Hariadi Kartodihardjo, Lala M. Kolopaking, Sudarsono Soedomo, (2015), Penggunaan Konsep Rules-In-Use Ostrom Dalam Analisis Peraturan Pembentukan Organisasi Kesatuan Pengelolaan Hutan (The Use of Ostrom's Concept on Rules-in-Use in the Analysis of Regulation of Forest Management Unit Formation), Jurnal Analisis Kebijakan Kehutanan Volume 12, Nomor 1.

Forest Watch Indonesia. (2014). Panduan Penilaian Kinerja Pembangunan KPH (Kesatuan Pengelolaan Hutan) di Indonesia.

Henry Subagio, (2014), Jaminan Akses Informasi dalam Perlindungan dan Pengelolaan Lingkungan Hidup (Rekomendasi Penguatan Hak Akses Informasi Lingkungan), Jurnal Hukum Lingkungan Indonesia, Volume 01, Issue 01.

Ifrani dan Yati Nurhayati, (2017), "The Enforcement of Criminal Law in the Utilization and Management of Forest Area Having Impact Toward Global Warming”, Sriwijaya Law Review, Vol.1 Issue.2, July 2017.

Ifrani, F.A. Abby, A. H. Barkatullah, Yati Nurhayati, M. Yasir Said, (2019), "Forest Management Based on Local Culture of Dayak Kotabaru in the Perspective of 
Customary Law for a Sustainable Future and Prosperity of the Local Community", Resources 8 (Issue 2).

Kartodihardjo H., Nugroho B., Putro HR., (2011), Pembangunan Kesatuan Pengelolaan Hutan (KPH): Konsep Peraturan Perundangan dan Implementasi. Jakarta: Kementerian Kehutanan Republik Indonesia.

M. Yasir Said dan Yati Nurhayati, (2020), "Paradigma Filsafat Etika Lingkungan Dalam Menentukan Arah Politik Hukum Lingkungan", Al-Adl:Jurnal Hukum, Volume VII Nomor 1 Januari 2020.

Mukhlis, Mustafa Lui, (2010), Hukum Administrasi Lingkungan Kontemporer Diskursus Pengawasan Pengelolaan Lingkungan Hidup dan Pengembangan Hukum Administrasi di Indonesia, Malang, Setara Press (Kelompok InTRANS Publishing).

OK Hasnanda Syahputra, Bramasto Nugroho, Hariadi Kartodihardjo, Nyoto Santoso, (2019), Pembelajaran Dari Kelembagaan Pengelolaan Mangrove Berbasis Masyarakat Di Kesatuan Pengelolaan Hutan Wilayah 3 Provins Aceh, Seminar Nasional KeIV Fakultas Pertanian Universitas Samudra "Pertanian Berkelanjutan Berbasis Sumber Daya Lokal di Era Revolusi Industri 4.0”, Volume 2, Nomor 1.

Senoaji, G. (2011). "Kondisi Sosisal Ekonomi Masyarakat Sekitar Hutan Lindung Bukit Daun di Bengkulu". Sosiohumaniora. Volume 13 (I), Nomor 1.

Suwari Akhmaddhian. (2020). "Wacana Pembuatan Pengadilan Lingkungan Khusus di Indonesia untuk Menyelesaikan Sengketa Lingkungan”. Jurnal Bestuur. Volume 8, Edisi 2.

Trisna Subarna, (2011), Faktor-Faktor yang Mempengaruhi Masyarakat Menggarap Lahan di Hutan Lindung: Studi Kasus di Kabupaten Garut Jawa Barat, Jurnal Penelian Sosial dan Ekonomi Kehutanan, Voume 8, Nomor 4.

Yati Nurhayati, (2013), Perdebatan Antara Metode Normatif Dengan Metode Empirik Dalam Penelitian Ilmu Hukum Ditinjau Dari Karakter, Fungsi, dan Tujuan Ilmu Hukum, Al Adl: Jurnal Hukum, Vol. 5, No. 10.

Yati Nurhayati, Ifrani, \& M. Yasir Said, (2021), Metodologi Normatif dan Empiris Dalam Perspektif Ilmu Hukum, Jurnal Penegakan Hukum Indonesia, Vol. 2, No.1, Tahun 2021.

\section{Internet}

Forest and Climate Change Programme (FORCLIME), Kesatuan Pengelolaan Hutan (KPH), "Pertanyaan yang sering diajukan", http://www.forclime.org/documents/Brochure/Bahasa/FAQ\%20KPH\%20_Bahasa .pdf 


\section{Lain-lain}

Direktorat Jenderal Planologi Kehutanan dan Tata Lingkungan Kementerian Lingkungan Hidup dan Kehutanan. (2016). "Pembangunan Kesatuan Pengelolaan Hutan".

Kartodihardjo H., (2011), Penanganan Konflik Kehutanan: Peran dan Pengalaman Dewan Kehutanan Nasional, Forum DKN untuk Mediasi Konflik, Disampaikan pada Kongres Kehutanan Indonesia (KKI) ke-V Tanggal 21-24 November 2011 di Gedung Manggala Wana Bakti, Jakarta. 